\title{
Thioderivatives of Resorcin[4]arene and Pyrogallol[4]arene: Are thiols tolerated in the self-assembly process?
}

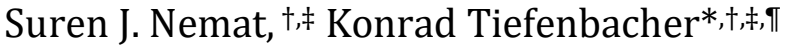 \\ AUTHOR ADDRESS \\ †Department of Chemistry, University of Basel, Mattenstrasse 24a, 4058 Basel, Switzerland; ₹ National Centre of \\ Competence in Research (NCCR) Molecular Systems Engineering, BPR 1095, Basel, Switzerland; "Department of \\ Biosystems Science and Engineering, ETH Zurich, Mattenstrasse 24, 4058 Basel, Switzerland
}

Supporting Information Placeholder

\begin{abstract}
Three novel thiol bearing resorcin[4]arene and pyrogallol[4]arene derivatives were synthesized. Their properties were studied with regards to self-assembly, Brønsted acid catalysis, and disulfide chemistry. One new thiosubstituted macrocycle stands out in particular, as it forms a hexameric capsule in $\mathrm{CDCl}_{3}$ capable of terpene cyclizations, dimerizes via disulfide bridges under mild oxidative conditions, and most importantly shows guest uptake of both alkyl ammonium salts and $\mathrm{C}_{60}$-fullerenes.
\end{abstract}

Macrocycles constitute a large proportion of molecules investigated in supramolecular chemistry. ${ }^{1}$ Phenolic macrocycles of the calix[4]arene family, in particular, have proven to be highly functional and versatile bowl-shaped building blocks. ${ }^{2}$ Calix[4]arene and its sister molecules resorcin[4]arene (RS) and pyrogallol[4]arene (PG) (Figure 1a) are obtained via simple one-step procedures and are even commercially available. They feature a rigid and easily derivatizable framework, ${ }^{3}$ enabling a multitude of applications in and beyond the field of supramolecular chemistry. ${ }^{4}$ Both RS and PG are capable of self-assembly in apolar solvents, forming hexameric capsules I and II through hydrogen bonding interactions. ${ }^{5}$ These supramolecular assemblies are capable of guest uptake ${ }^{6}$ and in the case of RS, the structure's interior serves as an enzyme-like catalytic pocket for numerous reactions. ${ }^{7}$

Sulfur-containing macrocycles have been of interest since the early days of supramolecular chemistry, starting with thioether bridged carcerands reported by Cram in the early 1980s (Figure 1b). ${ }^{8}$ Subsequently, several covalently linked thioether and also disulfide-containing carcerands and hemicarcerands with remarkable guest uptake capabilities have been reported. ${ }^{9}$ In particular, the reversibility of disulfide chemistry is of interest as it provides access to defined thermodynamically favored structures through dynamic covalent chemistry (DCvC). ${ }^{10}$ Besides these covalently linked sulfur-containing supramolecular containers also some non-covalently assembled structures have been reported. ${ }^{11}$ To this point, the application of sulfur in hydrogen-bonded systems has been limited to thiourea motifs, in which the thione serves as hydrogen bond acceptor in the self-assembly of dimeric capsules. ${ }^{12}$

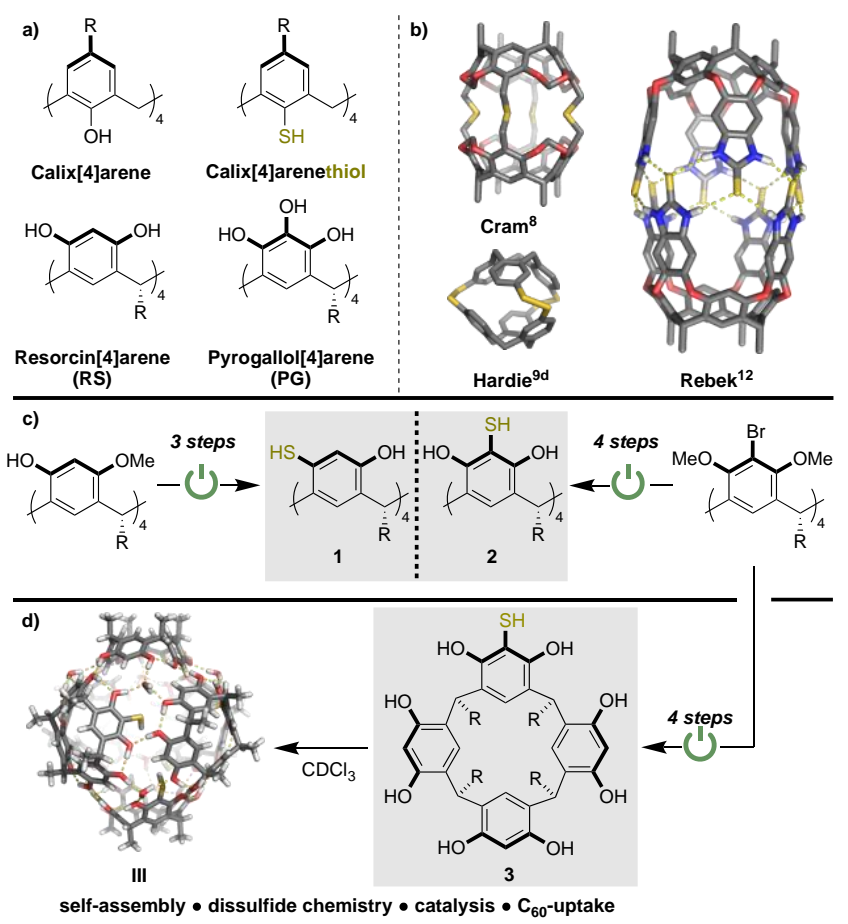

Figure 1. (a) Calix[4]arene family. (b) Selected sulfurcontaining supramolecular structures. (c) New tetrathiol calix[4]arenes $\mathbf{1}$ and 2. (d) Monothiolresorcin[4]arene $\mathbf{3}$ capable of self-assembly, disulfide chemistry, catalysis, and $\mathrm{C}_{60}$ fullerene and ammonium salt uptake. 
Phenol-bearing calix[4]arenes have been thoroughly investigated and some thiol derivatives have been synthesized and utilized to generate supramolecular structures. ${ }^{13}$ However, no sulfur analogs bearing both free phenols and thiols have been reported to our knowledge. In this work, we aimed to synthesize thiol derivatives of RS and $\mathbf{P G}$ in order to address the following three questions: (1) Are thiol-derivatives of $\mathbf{R S}$ and $\mathbf{P G}$ able to self-assemble to supramolecular capsules, despite the steric demands of the sulfur atoms? (2) Is the increased acidity of thiolcontaining capsules sufficient to catalyze terpene cyclizations, which presently require $\mathrm{HCl}$ as an acidic cocatalyst? ${ }^{7 b},{ }^{14}$ (3) Is it possible to covalently link thiolcontaining hydrogen-bond-based capsules via oxidative disulfide formation?

To answer these questions, three novel thiol derivatives were proposed, two of which are tetrathiol analogs of $\mathbf{R S}$ and PG, labeled $\mathbf{1}$ and $\mathbf{2}$ respectively (Figure 1c). Our previous studies on the resorcin[4]arene framework demonstrated that the number of substituents strongly affects the properties of the corresponding macrocycle. ${ }^{14 \mathrm{~b}}$ Therefore, an additional monothiol-RS derivative $\mathbf{3}$ was investigated (Figure 1d), in order to minimize potential disruptions of the hydrogen-bonding network due to the size of the large sulfur atom. We herein report the synthesis and characterization of these three novel macrocycles 1-3. Monothiol 3, in particular, stands out as it is capable of selfassembly, disulfide chemistry, catalysis, and guest uptake.

Most members of the calix[4]arene family can be obtained through electrophilic aromatic substitution of the respective phenols with aldehydes. ${ }^{15}$ However, due to the high nucleophilicity of the respective thiol building blocks, direct cyclizations of the corresponding mercaptophenols are unsuccessful. Therefore, an alternative route towards macrocycles 1-3 is required. For the synthesis of 1, readily available tetramethoxy resorcin[4]arene $\mathbf{5}^{16}$ (Scheme 1a) was used as the starting material. It has proven to be an excellent building block for multiple functionalized resorcin[4]arenes in the past. ${ }^{17}$ In the first step, $\mathbf{5}$ is converted into tetra- $O$-thiocarbamate $\mathbf{6}$. The applied conditions were adapted from related reactions on the resorcin[4]arene framework ${ }^{18}$ and optimized. Through the application of high-temperature microwave conditions, ${ }^{19} 6$ is converted into the corresponding tetra- $S$-thiocarbamate via Newman-Kwart rearrangement. Removal of the methyl protecting groups with boron tribromide and subsequent reduction of the $S$-thiocarbamate using modified conditions for related molecules ${ }^{13 e, 20}$ yields tetrathiol 1 in $16 \%$ overall yield over three steps.

Scheme 1. Synthesis ${ }^{a}$ of thioderivatives of RS and PG. (a,b) Synthesis of tetrathiols $\mathbf{1}$ and 2. (c) Synthesis of monothiol 3. (d) Synthesis of disulfides $\mathbf{1 0}$ and $\mathbf{3} . \mathrm{R}=\mathrm{C}_{11} \mathrm{H}_{23}$.

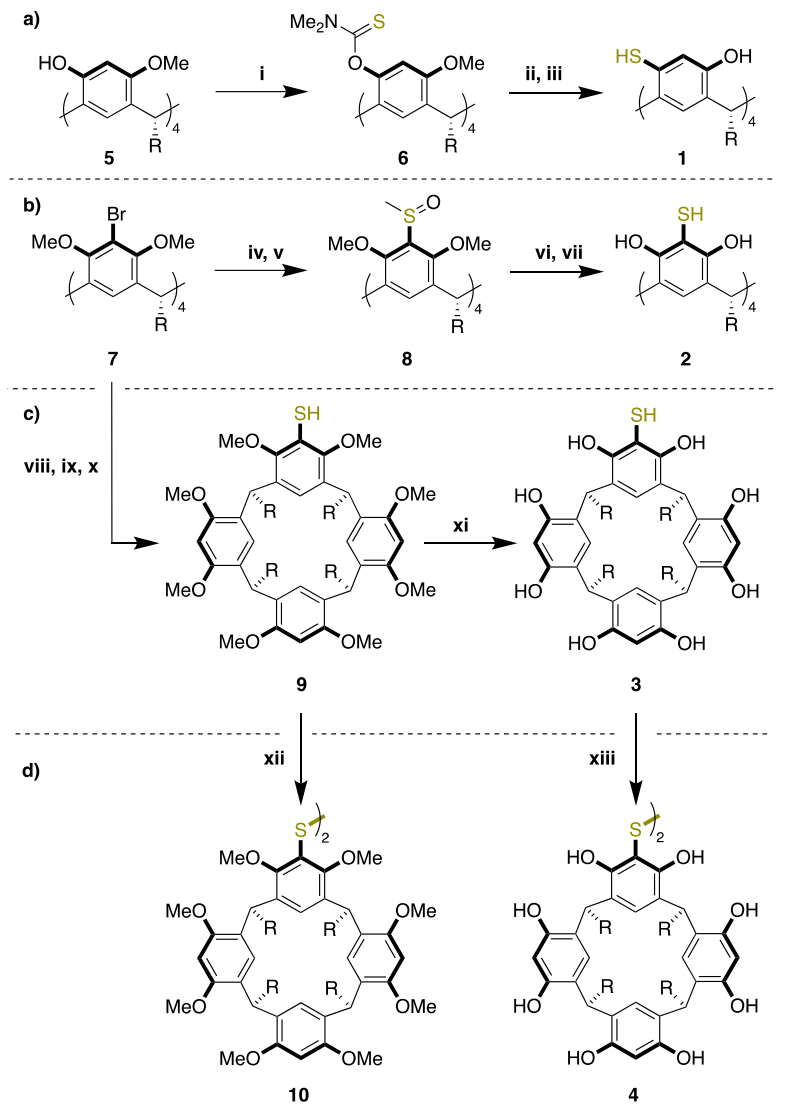

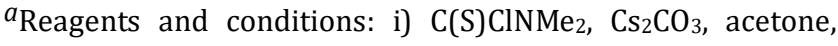
$77 \%$; ii) DMA, MW, $300{ }^{\circ} \mathrm{C}$, then $\mathrm{BBr}_{3}, \mathrm{DCM}, 72 \%$ over two steps; iii) $\mathrm{LiAlH}_{4}$, THF, 29\%; iv) $n \mathrm{BuLi}, \mathrm{S}_{2} \mathrm{Me}_{2}, \mathrm{THF}, 74 \%$; v) $m \mathrm{CPBA}, \mathrm{DCM}, 97 \%$; vi) 2,6-lutedine, TFAA, DCM, then NEt3, $\mathrm{MeOH}, 38 \%$, vii) $\mathrm{BBr}_{3}$, DCM, 91\%. viii) $n \mathrm{BuLi}, \mathrm{S}_{2} \mathrm{Me}_{2}$, THF, then $n \mathrm{BuLi}, \mathrm{MeOH}, 42 \%$; ix) mCPBA, DCM, 98\%; x) 2,6-lutedine, TFAA, DCM, then $\mathrm{NEt}_{3}, \mathrm{MeOH}, 92 \%$, xi) $\mathrm{BBr}_{3}, \mathrm{DCM}, 96 \%$. xii) $\mathrm{NEt}_{3}, \mathrm{I}_{2}, \mathrm{CHCl}_{3}, 92 \%$; xiii) DMSO- $d_{6}, \mathrm{CDCl}_{3}, 100 \%$.

For the synthesis of $\mathbf{2}$ a different approach for the aryl thiol introduction was chosen, as a suitably protected counterpart to $\mathbf{5}$ is not readily available. The protected and tetrabrominated compound $\mathbf{7}^{21}$ (Scheme $1 \mathrm{~b}$ ) was identified as an appropriate starting material. $\mathbf{7}$ enables the construction of carbon-sulfur bonds through bromolithium exchange, followed by quenching with dimethyl disulfide. ${ }^{22}$ The resulting methyl thioether is oxidized to the corresponding sulfoxide 8 with $m \mathrm{CPBA}^{20,}{ }^{23}$ Avoiding the use of superstochiometric amounts of $m$ CPBA in addition to the application of low reaction temperatures proved to be crucial for preventing overoxidation to the sulfone. A Pummerer rearrangement ${ }^{24}$ using modified literature conditions and subsequent removal of the methyl group protecting groups with boron tribromide yielded 2 in $22 \%$ overall yield over four steps. A similar synthetic route was followed for the monothiol macrocycle 3 (Scheme 1c). Following the installation of a single $S$-methyl moiety onto 7 and subsequent oxidation to the monosulfoxide, the octamethoxy monothiol $\mathbf{8}$ is accessed through the aforementioned Pummerer rearrangement. After deprotection, the RS-derivative 3 was obtained in $36 \%$ 
overall yield over four steps. All three macrocycles 1-3 were fully characterized by ESI-HRMS, NMR- and IRspectroscopy.

With all three thiol-bearing macrocycles at hand, we started investigating their individual properties. While $\mathbf{1}$ proved to be well soluble in chloroform, 2 showed poor solubility in all tested solvents $\left(\mathrm{CDCl}_{3}, \mathrm{CD}_{2} \mathrm{Cl}_{2}, \mathrm{TCE}-d_{2}\right.$, benzene- $d_{6}$, toluene- $d_{5}$ ). No evidence for self-assembly was obtained by NMR spectroscopy for either of these two macrocycles, even after the addition of potential templates (NMe ${ }_{4} \mathrm{I}, \mathrm{TBAI}, \mathrm{C}_{60}$-fullerene, pyrene). However, the formation of the hexameric assembly III in $\mathrm{CDCl}_{3}$ was observed for monothiol $\mathbf{3}$ as confirmed by DOSY-NMR (Supporting Information (SI), Figure S9, S12). These findings seem to affirm our assumptions regarding the disruption of the hydrogen bonding network with an increasing number of thiols due to the size of the sulfur atom.

Next, we investigated the potential of $\mathbf{1}$ and $\mathbf{2}$ to generate defined structures via disulfide bond formation. By screening conditions as applied to related systems, ${ }^{9 \mathrm{~d}, 25}$ we found that mild, reversible conditions such as the addition of base under air showed no conversion, while harsh conditions utilizing the strong oxidant $\mathrm{I}_{2}$ lead to oligomerization into undefined product mixtures. In consideration of both the absence of self-assembly and the oligomerization during disulfide formation, we concluded that (1) the aromatic thiols are disrupting the formation of a hydrogen-bonding network due to their size. According to molecular modeling, the thiols do not participate in the hydrogen bond network (SI, Chapter 3 ). The ${ }^{1} \mathrm{H}$ NMR spectra of compounds 1 and $\mathbf{2}$ in $\mathrm{CDCl}_{3}$ also do not provide indications for the participation of thiols in hydrogen bonding with neighboring phenols (SI, Figure S9). (2) The investigated tetrathiols require strong oxidative and irreversible conditions for disulfide formation, which precludes any DCvC and hence, the formation of defined disulfide bridged assemblies. However, resorcin[4]arene derivative $\mathbf{3}$ and its synthetic precursor $\mathbf{9}$ were expected to not suffer from the aforementioned issues. During the attempts to synthesize disulfide bridged dimers from 9 and 3 respectively, we found that for the former, the use of molecular iodine and base yielded the selective formation of disulfide 9 (Scheme 1d). Conversely, the exact same conditions led to decomposition in the case of the latter. Through further investigation, we were able to determine suitable conditions to induce disulfide formation from $\mathbf{3}$ via the literature known mild oxidant DMSO. ${ }^{26}$ The formation of dimeric disulfides $\mathbf{4}$ and $\mathbf{1 0}$ was confirmed by HRMS and NMR data, in particular DOSY-NMR (SI, Chapter 2.5).

DOSY-NMR measurements have been established as a reliable tool for the size determination of supramolecular capsules. ${ }^{27}$ In order to verify the disulfide formation for $\mathbf{4}$ and 10, $\mathrm{CDCl}_{3} / \mathrm{DMSO} 1: 1$, a polar solvent mixture that prevents self-assembly via hydrogen bonds, was chosen. A smaller DOSY value was observed for $\mathbf{4}$ as compared to its precursor 3 and the monomeric benchmark RS (Figure 2, SI, Table S1). A similar value was obtained for 10, providing strong evidence for the formation of dimeric species. To investigate the formation of assemblies from these disulfides, DOSY-NMR measurements in the apolar solvent $\mathrm{CDCl}_{3}$ were performed. Most interestingly, 4 appears to form the trimeric capsule IV of similar dimensions as the systems I-III.

\begin{tabular}{lccccccc} 
DOSY Solvent & $\mathbf{1}$ & $\mathbf{2}$ & $\mathbf{3} / \mathrm{II}$ & $\mathbf{4} / \mathrm{IV}^{c}$ & $\mathrm{RS} / \mathrm{I}$ & $\mathrm{PG} / \mathrm{Il}$ & $1^{c}$ \\
\hline CDCl$_{3} /$ DMSO- $_{6}(\mathbf{1 : 1 )}$ & $-a$ & $-a$ & 0.16 & 0.12 & 0.16 & $-b$ & 0.11 \\
$\mathrm{CDCl}_{3}$ & 0.40 & $-b$ & 0.23 & 0.24 & 0.24 & 0.24 & 0.45 \\
& & & & & & & \\
\hline
\end{tabular}

Figure 2. DOSY values for macrocycles $(20 \mathrm{mM})$ and assemblies. ${ }^{a}$ Rapid oligomerization. $b$ Macrocycle insoluble in given NMR-solvent. ${ }^{c}$ Dimeric species measured at $10 \mathrm{mM}$.

With capsule III at hand, we began investigating its properties as a catalyst for terpene cyclizations. Test reactions with nerol and geraniol demonstrated no significant conversion, while geranylacetate suffered from nucleophilic attack by 3's thiol, leading to alkylation and subsequent disassembly of III (SI, Figure S28). Therefore, we conclude that the increased acidity of III (SI, Chapter 5) is not sufficient to catalyze terpene cyclizations on its own. Next, we investigated potential differences in the terpene cyclization with $\mathrm{HCl}$ as a co-catalyst in direct comparison to I (Figure 3a). A very similar product distribution for the cyclization of nerol and geraniol was obtained for I and III (SI, Chapter 4). At the same time, the reactions with III proceeded slower and showed a more significant background reaction when the capsules were blocked by the strongly binding alkylammonium guest TBAB. The slower reaction and the stronger background conversion might be a result of the weaker hydrogen bond network caused by the presence of the sterically demanding thiols; in other words, a decreased overall stability of III. To gain insight into the strength of the hydrogen bonding network, a DOSY-NMR titration with MeOD was performed (Figure 3 b, SI, Chapter 6). ${ }^{28}$ It is evident that III is less stable than its relatives I and II, as it disassembles at much lower methanol concentrations. 

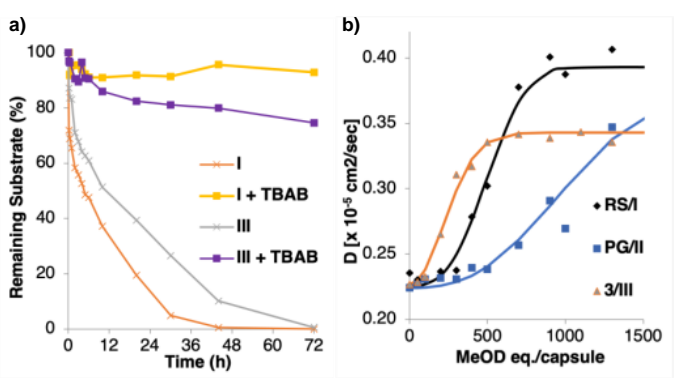

c)

$\mathrm{C}_{60}$
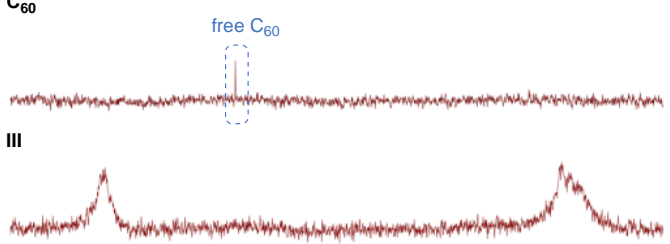

III $+\mathrm{C}_{60}$

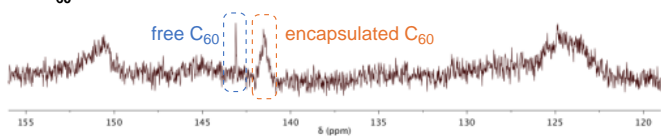

Figure 3. (a) Nerol conversion by I and III via HCl-cocatalyzed terpene cyclization conditions and controls blocked by TBAB. (b) Stability of hexamers I-III towards the protic solvent MeOD as characterized by the change in DOSY-value upon titration. (c) $\mathrm{C}_{60}$-fullerene uptake studies by ${ }^{13} \mathrm{C}-\mathrm{NMR}$ in $\mathrm{CDCl}_{3}: \mathrm{C}_{60^{-}}$ fullerene (1.33 mM); Capsule III (2.00 mM); Capsule III (1.33 $\mathrm{mM})$ and $\mathrm{C}_{60}$-fullerene $(1.33 \mathrm{mM})$.

Finally, the guest uptake capability of capsule III was analyzed. Based on the results of the capsule catalysis and further NMR experiments, it becomes clear that III is capable to take up alkyl ammonium salts such as TBAB (SI, Chapter 7). This was expected as the capsule possesses a similar hydrogen-bonding network as I, capable of anion stabilization.6e Surprisingly though, also $\mathrm{C}_{60}$-fullerene uptake was observed in III (Figure 3c). The ability to encapsulate fullerenes comes as a surprise since both $\mathbf{I}$ and II are incapable to function as hosts for this type of guest (SI, Figures S34-35). To our knowledge, no hydrogen-bonded capsule has been reported to encapsulate both alkylammonium salts and fullerenes before. ${ }^{14 \mathrm{~b}, 29}$

In summary, we have demonstrated the applicability of two distinct methods to install thiols on the resorcin[4]arene framework. These protocols allowed us to synthesize three novel thiol-analogues of resorcin[4]arene and pyrogallol[4] arene, investigate the influence of free thiols on their properties and compare them to RS and PG. Through extensive analysis, we found that: (1) Thiolderivatives of $\mathbf{R S}$ can self-assemble into a hexameric capsule III as long as the amount of thiols is kept to a minimum. (2) The increased acidity introduced by the six thiols of III is not sufficient to catalyze terpene cyclizations on its own. (3) Disulfide formation with thiol-derivatized resorcin[4]renes is possible but requires irreversible oxidative conditions. Thus, it is limited to mono-thiols per macrocycle in order to prevent oligomerization and is not suited for DCvC. The dimeric disulfide 4 obtained under mild oxidative conditions from $\mathbf{3}$ forms a trimeric capsule
IV of similar size as capsules I-III, as confirmed by DOSYNMR studies. In addition to encapsulating alkylammonium salts, III can host $\mathrm{C}_{60}$-fullerene. This differentiates supramolecular structure III from other hydrogen-bonded capsules that can only encapsulate one or the other, but not both. We attribute this property to decreased overall stability of III.

\section{ASSOCIATED CONTENT}

Supporting Information

Experimental details and NMR spectra of new compounds (PDF)

\section{AUTHOR INFORMATION}

Corresponding Author

Konrad Tiefenbacher - Department of Chemistry, University of Basel, 4058 Basel, Switzerland; Department of Biosystems Science and Engineering, ETH Zurich, 4058 Basel, Switzerland; orcid.org/0000-0002-3351-6121;

Email: konrad.tiefenbacher@unibas.ch, tkonrad@ethz.ch

Authors

Suren J. Nemat - Department of Chemistry, University of Basel, 4058 Basel, Switzerland; orcid.org/0000-0002-1894-4021

Notes

The authors declare no competing financial interest.

\section{ACKNOWLEDGMENT}

This work was supported by funding from the Swiss National Science Foundation (Grant SNF: 200021_178714) and by the NCCR Molecular Systems Engineering The authors thank Dr. Michael Pfeffer for HR-MS analysis.

\section{REFERENCES}

(1) (a) Diederich, F.; Stang, P. J.; Tykwinski, R. R., Modern Supramolecular Chemistry: Strategies for Macrocycle Synthesis. Wiley-VCH: Weinheim, 2008. (b) Steed, J. W.; Atwood, J. L., Supramolecular Chemistry. John Wiley \& Sons Ltd.: Chichester, 2009. (c) Steed, J. W.; Gale, P. A., Supramolecular Chemistry: From Molecules to Nanomaterials. John Wiley \& Sons Ltd.: Chichester, 2012. (d) Atwood, J. L.; Gokel, G. W.; Barbour, L. J., Comprehensive Supramolecular Chemistry II. Elsevier: Oxford, 2017.

(2) (a) Gutsche, C. D., Calixarenes Revisited. The Royal Society of Chemistry: Cambridge, 1998. (b) Gutsche, C. D., Calixarenes: An Introduction. The Royal Society of Chemistry: Cambridge, 2008.

(3) (a) Timmerman, P.; Verboom, W.; Reinhoudt, D. N. Tetrahedron 1996, 52, 2663. (b) Asfari, Z.; Böhmer, V.; Harrowfield, J.; Vicens, J.; Saadioui, M., Calixarenes 2001. Kluwer Academic Publishers: Dordrecht, 2001. (c) Lavendomme, R.; Zahim, S.; De Leener, G.; Inthasot, A.; Mattiuzzi, A.; Luhmer, M.; Reinaud, O.; Jabin, I. Asian J. Org. Chem. 2015, 4, 710. (d) Kobayashi, K.; Yamanaka, M. Chem. Soc. Rev. 2015, 44, 449. (e) Scott, M. P.; Sherburn, M. S., 
Resorcinarenes and Pyrogallolarenes. In Comprehensive Supramolecular Chemistry II; Elsevier: Oxford, 2017; pp 337374.

(4) (a) Nimse, S. B.; Kim, T. Chem. Soc. Rev. 2013, 42, 366. (b) Kumar, R.; Sharma, A.; Singh, H.; Suating, P.; Kim, H. S.; Sunwoo, K.; Shim, I.; Gibb, B. C.; Kim, J. S. Chem. Rev. 2019, 119, 9657.

(5) (a) MacGillivray, L. R.; Atwood, J. L. Nature 1997, 389, 469. (b) Gerkensmeier, T.; Iwanek, W.; Agena, C.; Fröhlich, R.; Kotila, S.; Näther, C.; Mattay, J. Eur. J. Org. Chem. 1999, 1999, 2257.

(6) (a) Shivanyuk, A.; Rebek, J. Proc. Natl. Acad. Sci. U.S.A. 2001, 98, 7662. (b) Avram, L.; Cohen, Y. J. Am. Chem. Soc. 2002, 124, 15148. (c) Avram, L.; Cohen, Y. J. Am. Chem. Soc. 2003, 125, 16180. (d) Avram, L.; Cohen, Y.; Rebek Jr, J. Chem. Commun. 2011, 47, 5368. (e) Zhang, Q.; Catti, L.; Kaila, V. R. I.; Tiefenbacher, K. Chem. Sci. 2017, 8, 1653.

(7) (a) Cohen, Y.; Slovak, S.; Avram, L., Hydrogen Bond Hexameric Capsules: Structures, Host-Guest Interactions, Guest Affinities, and Catalysis. In Calixarenes and Beyond; Springer International Publishing: Cham, 2016; pp 811-842. (b) Zhang, Q.; Catti, L.; Tiefenbacher, K. Acc. Chem. Res. 2018, 51, 2107. (c) Gaeta, C.; Talotta, C.; De Rosa, M.; La Manna, P.; Soriente, A.; Neri, P. Chem. Eur. J. 2019, 25, 4899. (d) Zhu, Y.; Rebek Jr, J.; Yu, Y. Chem. Commun. 2019, 55, 3573.

(8) Cram, D. J.; Karbach, S.; Kim, Y. H.; Baczynskyj, L.; Kallemeyn, G. W. J. Am. Chem. Soc. 1985, 107, 2575.

(9) (a) Jasat, A.; Sherman, J. C. Chem. Rev. 1999, 99, 931. (b) Warmuth, R., Carcerands and Hemicarcerands. In Supramol. Chem.; 2012. (c) Margetić, D., 6.06 - Carcerands and Hemicarcerands. In Comprehensive Supramolecular Chemistry II; Elsevier: Oxford, 2017; pp 115-137. (d) Little, M. A.; Donkin, J.; Fisher, J.; Halcrow, M. A.; Loder, J.; Hardie, M. J. Angew. Chem. Int. Ed. 2012, 51, 764.

(10) (a) Rowan, S. J.; Cantrill, S. J.; Cousins, G. R. L.; Sanders, J. K. M.; Stoddart, J. F. Angew. Chem. Int. Ed. 2002, 41, 898. (b) Corbett, P. T.; Leclaire, J.; Vial, L.; West, K. R.; Wietor, J.-L.; Sanders, J. K. M.; Otto, S. Chem. Rev. 2006, 106, 3652.

(11) (a) Riwar, L.-J.; Trapp, N.; Root, K.; Zenobi, R.; Diederich, F. Angew. Chem. Int. Ed. 2018, 57, 17259. (b) Zhu, Y.-J.; Gao, Y.; Tang, M.-M.; Rebek, J.; Yu, Y. Chem. Commun. 2021, 57, 1543. (12) Asadi, A.; Ajami, D.; Rebek, J. J. Am. Chem. Soc. 2011, 133, 10682.

(13) (a) Ting, Y.; Verboom, W.; Groenen, L. C.; van Loon, J.-D.; Reinhoudt, D. N. J. Chem. Soc., Chem. Commun. 1990, 1432. (b) Gibbs, C. G.; Gutsche, C. D. J. Am. Chem. Soc. 1993, 115, 5338. (c) Gibbs, C. G.; Sujeeth, P. K.; Rogers, J. S.; Stanley, G. G.; Krawiec, M.; Watson, W. H.; Gutsche, C. D. J. Org. Chem. 1995, 60, 8394. (d) Delaigue, X.; Harrowfield, J. M.; Hosseini, M. W.; De Cian, A.; Fischer, J.; Kyritsakas, N. J. Chem. Soc., Chem. Commun. 1994, 1579. (e) Helgeson, R. C.; Knobler, C. B.; Cram,
D. J. J. Chem. Soc., Chem. Commun. 1995, 307. (f) Irwin, J. L.; Sherburn, M. S. Org. Lett. 2001, 3, 225.

(14) (a) Köster, J. M.; Tiefenbacher, K. ChemCatChem 2018, 10 , 2941. (b) Merget, S.; Catti, L.; Piccini, G.; Tiefenbacher, K. J. Am. Chem. Soc. 2020, 142, 4400.

(15) (a) Baeyer, A. Ber. Dtsch. Chem. Ges. 1872, 5, 280. (b) Niederl, J. B.; Vogel, H. J. J. Am. Chem. Soc. 1940, 62, 2512. (c) Zinke, A.; Kretz, R.; Leggewie, E.; Hössinger, K.; Hoffmann, G.; Weber v. Ostwalden, P.; Wiesenberger, E.; Sobotka, M.; Kretz, R. Monatsh. Chem. 1952, 83, 1213.

(16) McIldowie, M. J.; Mocerino, M.; Skelton, B. W.; White, A. H. Org. Lett. 2000, 2, 3869.

(17) (a) Nemat, S. J.; Jędrzejewska, H.; Prescimone, A.; Szumna, A.; Tiefenbacher, K. Org. Lett. 2020, 22, 5506. (b) Nemat, S. J.; Van den Eynden, D.; Deblock, L.; Heilmann, M.; Köster, J. M.; Parvizian, M.; Tiefenbacher, K.; De Roo, J. Chem. Commun. 2021, 57, 4694.

(18) Tarasenko, D. V.; Serkova, O. S.; Vasyanina, L. K.; Maslennikova, V. I. Tetrahedron Lett. 2016, 57, 177.

(19) Moseley, J. D.; Lenden, P. Tetrahedron 2007, 63, 4120.

(20) Sanseverino, J.; Chambron, J.-C.; Aubert, E.; Espinosa, E. J. Org. Chem. 2011, 76, 1914.

(21) (a) Cram, D. J.; Karbach, S.; Kim, H. E.; Knobler, C. B.; Maverick, E. F.; Ericson, J. L.; Helgeson, R. C. J. Am. Chem. Soc. 1988, 110, 2229. (b) Timmerman, P.; van Mook, M. G. A.; Verboom, W.; van Hummel, G. J.; Harkema, S.; Reinhoudt, D. N. Tetrahedron Lett. 1992, 33, 3377. (c) Pietraszkiewicz, M.; Prus, P.; Pietraszkiewicz, O. Tetrahedron 2004, 60, 10747. (22) (a) Kleinhans, D. J.; Arnott, G. E. J. Chem. Soc., Dalton Trans. 2010, 39, 5780. (b) Ngodwana, L.; Kleinhans, D. J.; Smuts, A.-J.; van Otterlo, W. A. L.; Arnott, G. E. RSC Adv. 2013, $3,3873$.

(23) (a) Sansévérino, J.; Aubert, E.; Espinosa, E.; Chambron, J.C. Eur. J. Org. Chem. 2012, 2012, 2225. (b) Brégier, F.; Lavalle, J.; Chambron, J. C. Eur. J. Org. Chem. 2013, 2013, 2666.

(24) Gamba-Sánchez, D.; Garzón-Posse, F., Pummerer-Type Reactions as Powerful Tools in Organic Synthesis. In Molecular Rearrangements in Organic Synthesis; 2015; pp 661-702. (25) (a) Little, M. A.; Halcrow, M. A.; Hardie, M. J. Chem. Commun. 2013, 49, 1512. (b) Brégier, F.; Hudeček, O.; Chaux, F.; Penouilh, M.-J.; Chambron, J.-C.; Lhoták, P.; Aubert, E.; Espinosa, E. Eur. J. Org. Chem. 2017, 2017, 3795.

(26) Epstein, W. W.; Sweat, F. W. Chem. Rev. 1967, 67, 247.

(27) Avram, L.; Cohen, Y. Chem. Soc. Rev. 2015, 44, 586. (28) Avram, L.; Cohen, Y. J. Am. Chem. Soc. 2004, 126, 11556. (29) (a) Beaudoin, D.; Rominger, F.; Mastalerz, M. Angew. Chem. Int. Ed. 2016, 55, 15599. (b) Markiewicz, G.; Jenczak, A.; Kołodziejski, M.; Holstein, J. J.; Sanders, J. K. M.; Stefankiewicz, A. R. Nat. Commun. 2017, 8, 15109. 